\title{
NCAM: a surface marker for human small cell lung cancer cells
}

\author{
Maria C. Aletsee-Ufrecht ${ }^{1}$, Keith Langley ${ }^{2}$, Martin Rotsch ${ }^{3}$, Klaus Havemann ${ }^{3}$ and Manfred Gratzl ${ }^{1}$ \\ ${ }^{1}$ Abteilung Anatomie und Zellbiologie der Universität Ulm, Albert-Einstein-Allee 11, D-7900 Ulm, FRG, ${ }^{2}$ INSERM U44, Centre de \\ Neurochimie du CNRS, 5 rue Blaise Pascal, 67084 Strasbourg Cedex, France and ${ }^{3}$ Abteilung Hämatologie/Onkologie, Zentrum für \\ Innere Medizin der Philipps-Universität Marburg, Baldingerstraße, D-3550 Marburg, FRG
}

Received 18 May 1990

\begin{abstract}
Immunocytochemical and immunochemical techniques were used to study the expression of the neural cell adhesion molecule (NCAM) by human lung cancer cell lines. Intense surface staining for NCAM was found at light and electron microscopic levels on small cell lung cancer cells. The NCAM polypeptide of $M_{\mathrm{r}} 140000$ (NCAM 140) was detected by immunoblotting in all of 7 small cell lung cancer cell lines examined and in one out of two of the closely related large cell cancer cell lines: it was not detected in cell lines obtained from one patient with a mesothelioma, in two cases of adenocarcinoma, nor in two cases of squamous cell cancer. In contrast, neuron-specific enolase was found by immunoblotting in all the lung cancer cell lines tested and synaptophysin in all but the adenocarcinoma cell lines. These antigens were localized intracellularly. The specific expression of NCAM 140 by human small and large cell lung carcinomas suggests its potential as a diagnostic marker.
\end{abstract}

Lung cancer; Neural cell adhesion molecule; Marker

\section{INTRODUCTION}

The small cell lung cancer (SCLC) is the most malignant human tumor of the lung. It comprises about onethird of all lung tumors in man and is characterized by early metastases and short survival. The association of paraneoplastic syndromes with small cell lung cancer is indicative of the endocrine nature of this tumor. Indeed, several 'neuroendocrine' marker proteins have been shown to occur in SCLC (cf. [1]). Several immunocytochemical or immunological markers are currently used to characterize different endocrine tumors. Certain markers, such as neuron-specific enolase (NSE) and synaptophysin (SYN), appear to be widespread in all types of neuroendocrine tumors, while others such as chromogranin A have more limited expression (cf. [2-5]). The addition of further specific markers to the range already employed could be very useful in establishing the diagnosis of certain neuroendocrine tumors. Most markers used to date have an intracellular localization. Cell surface molecular markers, because of their greater accessibility to external probes, have considerable advantages over cytoplasmic markers and could provide excellent tools to monitor tumor cells in the body.

Recently a cell surface molecule, the neural cell adhesion molecule (NCAM), has been shown to be a characteristic component of rat endocrine cells and its

Correspondence address: M. Gratzl, Abteilung Anatomie und Zellbiologie der Universität Ulm, Postfach 4066, D-7900 Ulm, FRG tumors [6,7]. In addition, while in central nervous tissues NCAM occurs as three isoforms of molecular masses 180,140 and $120 \mathrm{kDa}$, the NCAM isoform most characteristic of rat endocrine tissues is that of $140 \mathrm{kDa}$ (NCAM 140).

Interestingly, NCAM and SYN were amongst the earliest detected nervous tissue-specific proteins, first described under the names of $D_{2}$ and synaptin $([8,9]$ see also [10]). Subsequently the cellular and molecular biology of these proteins has been well documented (cf. $[11,12,13,14])$.

In this study we first examine the expression of NCAM in cell lines established from patients with different lung tumors and then compare its occurrence with that of the intracellular marker substances NSE and SYN. Seven different human small cell and 7 nonsmall cell carcinoma cell lines (large cell carcinoma, adenocarcinoma, squamous cell carcinoma, mesothelioma) were analyzed. While NSE was detected in all of the lung cancer cell lines tested, SYN was found in all cell lines except the adenocarcinomas. By contrast, the expression of NCAM was restricted, with the exception of one large cell carcinoma, to small carcinoma cell lines where it was localized on the cell surface membrane.

The specific expression of NCAM as a marker by small cell carcinoma cells and its occurrence on the cell surface suggest that the analysis of this molecule could serve as an excellent diagnostic tool. The presence of NCAM could also be used for the detection and targeting of small cell carcinoma primary tumors and metastases. 


\section{MATERIALS AND METHODS}

\subsection{Tissue cultures}

The human cell lines used in this study included the small cell lung cancer (SCLC) cell lines NCI-H60, NCI-N417, NCI-N592, SCLC$86 \mathrm{M} 1$, SCLC-21H, SCLC-22H, SCLC-24H, the non-SCLC cell lines LCLC-103H and LCLC-97TMI (large cell lung carcinoma), H125 and A459 (adenocarcinoma), EPLC-65H and EPLC-32M1 (cell lines originating from squamous cell carcinoma), and MSTO-211H (mesothelioma). Details concerning the patients, the establishment and characterization of the cell lines have been described in detail elsewhere [15-19]. All SCLC lines grew as suspension cultures and the non-SCLC lines grew adherent in RPMI 1640 medium (Gibco Europe, Paisley, UK) supplemented with $10 \%(\mathrm{v} / \mathrm{v})$ fetal calf serum (Gibco).

\subsection{Light and electron microscopy}

The SCLC-24H cells used for morphological studies were attached to poly-L-ornithine $(30 \mu \mathrm{g} / \mathrm{ml}$; Sigma, München, FRG) coated plastic dishes for $3 \mathrm{~h}$ and then fixed in freshly prepared phosphate-buffered $(0.1 \mathrm{M}, \mathrm{pH} 7.2) / 4 \%$ paraformaldehyde for $30 \mathrm{~min}$. For detection of NSE and SYN, cells were first treated with $10 \%$ methanol $/ 0.3 \%$ hydrogen peroxide in Tris-buffered saline for $5 \mathrm{~min}$ to block endogenous peroxidase activity and then permeabilized ( $5 \mathrm{~min}$ ) with $0.5 \%$ Triton X-100 in Tris-buffered saline. All cells were preincubated in $2 \%$ normal swine serum for $30 \mathrm{~min}$ and then, overnight at $4{ }^{\circ} \mathrm{C}$, in primary antiserum diluted in $2 \%$ normal swine serum in Trisbuffered saline. The antisera used in this study were raised in rabbits. Anti-human neuron-specific enolase (dilution $1: 1000$ ) was obtained from Dakopatts (Copenhagen, Denmark). Anti-NCAM (dilution 1:500) directed against an undecapeptide present in the aminoterminal of the mouse neural cell adhesion molecule and rat antisynaptophysin (dilution $1: 250$ ) have been previously characterized $[20,21]$. The antiserum (G95) was raised against affinity-purified SYN from rat brain. On rat brain sections it produced a staining pattern identical to that of another SYN antiserum (G62; R. Jahn, personal communication), the specificity of which has been documented in detail [21]. The immunoreaction was visualized by the peroxidaseantiperoxidase method [22] using reagents obtained from Dakopatts (Denmark). Labelled cells were viewed with an invertoscope (Zeiss). The preparation of cells for immunofluorescence and electron microscopy of NCAM was as previously described [7].

\subsection{Electrophoresis and immunoblotting}

Cells were lysed in sample buffer $(62.5 \mathrm{mM}$ Tris, $2 \%$ SDS, $10 \%$ sucrose, $\mathrm{pH}$ 6.8) by sonication. The extracted proteins were reduced with dithiothreitol (Sigma), alkylated as described [23] with iodoacetamide (Fluka, Buchs, Switzerland) and subjected to SDSPAGE $(7.5 \%)$. Immunoblots were prepared as previously described [24]. Blots were incubated with antibodies to NCAM (1:1000), NSE $(1: 3000)$ and SYN $(1: 5000)$.

\section{RESULTS AND DISCUSSION}

The specific aim of the present study was to detect marker substances exposed on the cell surface of lung cancer cells which could be useful for monitoring both primary tumors and metastases. The analysis of such molecules would complement determinations of intracellular marker molecules released from tumor cells during cell lysis, like NSE or SYN, which are currently used in clinical practice.

The recent observation of neural cell adhesion molecules (NCAMs) in endocrine cells [6,7] and the neuroendocrine nature of certain lung cancer types (cf. [1]) suggested that these surface molecules may be pres- ent in a significant fraction of lung tumors. In testing this suggestion we chose to examine tumor cell lines derived from different kinds of human lung cancers thus avoiding difficulties due to the heterogeneity of tissue samples [15-19]. These authors have shown that the endocrine phenotype is fully conserved by the tumor cells in culture.

Immunocytochemical studies, with two different methods, revealed an intense staining of the surface of human small cell carcinoma (Fig. 1a,b) with antibodies directed against NCAM. The exclusive localization of the immunoreaction at the cell surface contrasts with the staining pattern obtained with antibodies against the intracellular proteins SYN (Fig. 1c), and NSE (Fig. 1d).

The presence of NCAM at the plasma membrane of SCLC was confirmed by immunocytochemistry at the ultrastructural level (Fig. 2). This indicates that immunocytochemical techniques are sufficiently sensitive to detect NCAM in these tumor cells.

The NCAM gene has a complex intron/exon structure which, after alternative splicing of the primary transcript, gives rise to a group of mRNAs of different sizes coding for 3 proteins of molecular masses of 180 , 140 and $120 \mathrm{kDa}$, termed NCAM 180, NCAM 140 and NCAM 120 (cf. [11]). In immunoblots NCAM 140 has been detected in 7 different human cell lines of the small cell type (Fig. 3a). Thus these cells express the same NCAM isoform, which appears to be the most characteristic NCAM isoform in rat endocrine tissues and rat endocrine tumor cell lines $[6,7]$ and in these endocrine tissues. Lane 7 (Fig. 3a) is the immunoblot corresponding to the immunocytochemical data shown in Figs 1 and 2 (cell lines SCLC-24H). The intensity of the band corresponding to NCAM 140 varied noticeably from one cell line to another (compare lanes 1, 3 and 6 with lanes 4 and 5 in Fig. 3a) indicating that the amount of NCAM 140 at the cell surface of different tumor cells varies. Moreover, these data reveal a large difference in the expression of NCAM 140 in cell lines SCLC-21H (Fig. 3a, lane 5) and SCLC-22H (Fig.3a, lane 6) which are derived from the same patient: in fact, levels of both NCAM 140 and SYN are lower in SCLC-21H than in SCLC-22H. In contrast, NSE levels are higher in SCLC-21H (Fig. 3b). Since identical amounts of protein were used for each blot this indicates that the expression of NCAM in small cell lung carcinoma cells varies during the course of the disease. Furthermore it is clear that the expression of several markers is regulated in different directions, which is in agreement with the differences in several other criteria observed earlier [16]. This may explain the fact that certain markers typical of endocrine cells are sometimes difficult to detect in certain tumors or at certain tumor stages. In addition to the small cell carcinoma cell lines, the large cell line (LCLC-103 H in lane 8), but not the large cell line (LCLC 97TM1, lane 9) shows a band cor- 

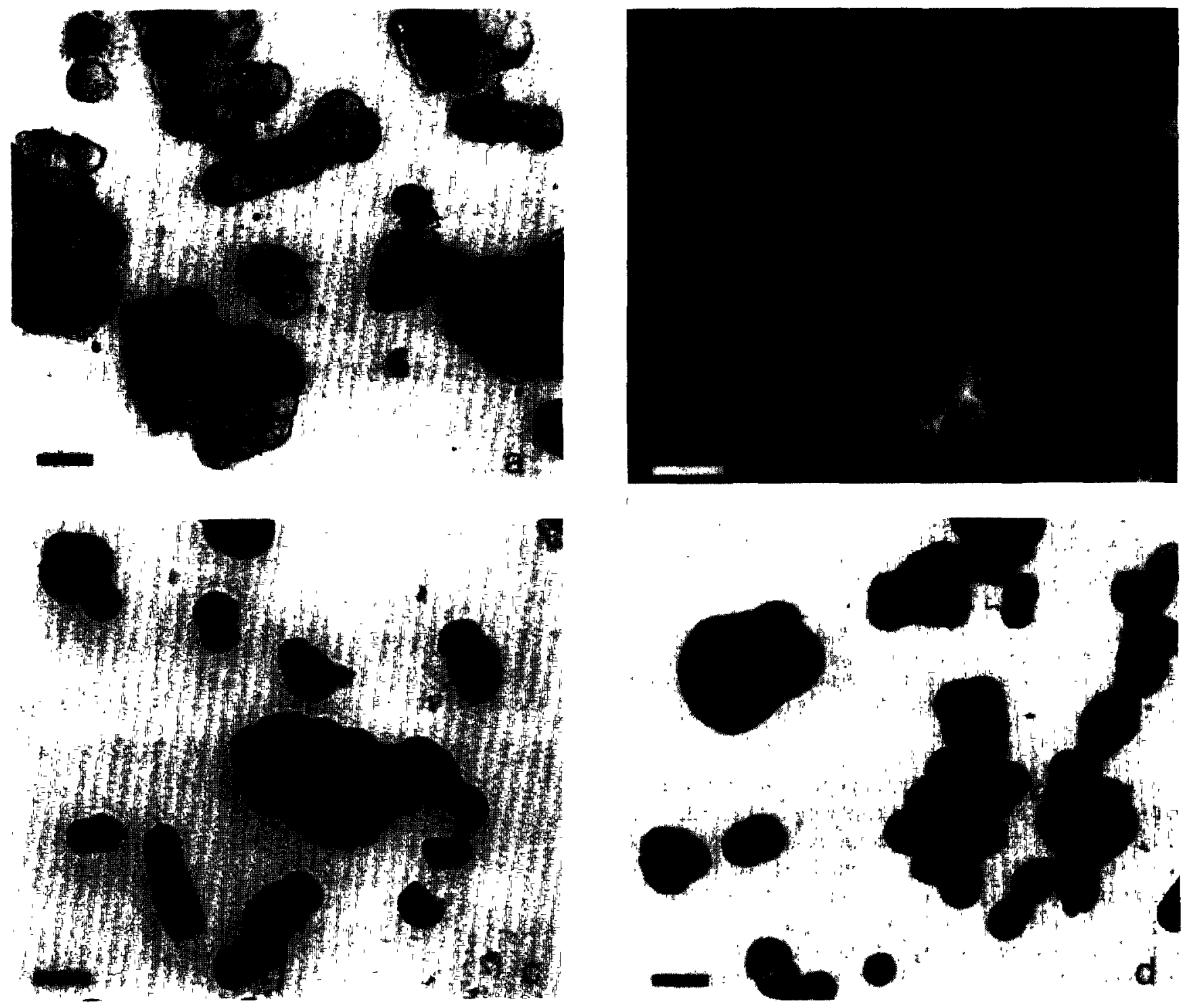

Fig. 1. Immunolocalization of NCAM (a,b), SYN (c) and NSE (d) in SCLC cells (SCLC-24H). Note the exclusive surface labelling of NCAM in contrast to the intracellular staining of NSE and SYN38. Bars $=20 \mu \mathrm{m}$. (a,c,d) immunocytochemistry by the indirect peroxidase-antiperoxidase method; (b) immunofluorescence.

responding to NCAM 140 suggesting that occasionally these non-SCLC tumors may share the expression of this surface molecule. This finding would support the belief that SCLC cell lines may change their morphological appearance and become large cell carcinoma [16,25].

In contrast to small cell lung cancer cell lines, no NCAM 140 was detected in squamous cell carcinoma (Fig. 3a, lanes 10 and 11), mesothelioma (Fig. 3a, lane 12) or adenomacarcinoma cell lines (Fig. 3a, lanes 13 and 14). This clear-cut difference in NCAM 140 expression is of great potential value for the diagnosis of different lung cancer types which represents a crucial prerequisite for the mode of treatment of these human tumors.
Endocrine cells, classified originally as APUD (amine precursor uptake and decarboxylation) cells share a number of morphological and biochemical properties [26] that have led pathologists to use proteins common to these cells as markers for diagnostic purposes. No single ideal protein marker exists for endocrine cells. The two proteins NSE and SYN most commonly employed are sometimes unequally expressed by different endocrine tumors. Indeed, as pointed out above, their levels may vary in tumor cells removed at different times from the same patient. This problem of sensitivity of methods to detect markers is particularly acute for proteins which are considered to be good markers of secretion granules in normal endocrine cells, such as chromogranin A. Secretion granules are often relatively 


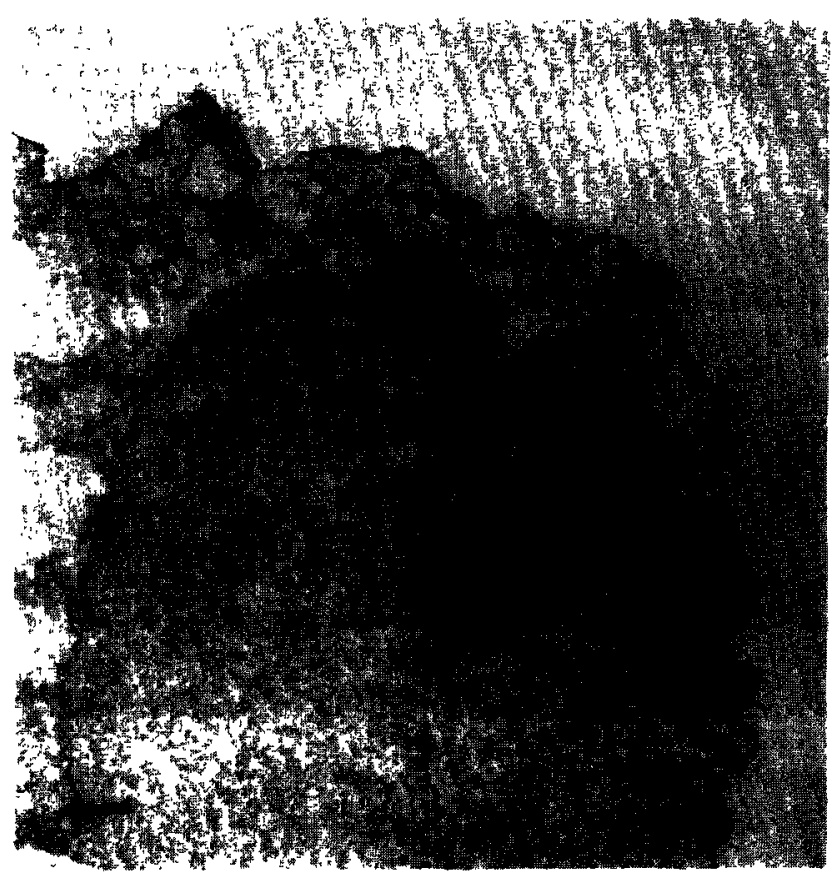

Fig. 2. Electron micrograph of SCLC cells (SCLC-24H) labelled for NCAM. The immunoreaction is restricted to the cell surface, no detectable levels of antigen are found intracellularly. Section not counterstained. Bar $=1 \mu$.

scarce in cells that have undergone malignant transformation, which probably explains why SCLC cells are often negative for chromogranin $\mathbf{A}$ in immunocytochemistry $[27,28]$ and why serum levels of this particular protein are either not or only moderately raised in patients suffering from small cell lung cancer [29]. Thus it is essential to extend the range of potential markers that can be employed to detect neoplastic cells with high sensitivity in order to distinguish not only endocrine from other tumor types, but also to differentiate between different types of endocrine tumors.

The presence of SYN in lung tumors has been reported previously $[3,30]$. The data shown in Fig. 3c show that it is also expressed in non-endocrine lung tumor cells except adenocarcinomas. Similarly, NSE has been detected in non-SCLC $[25,31,32]$ and also in other human tissues and neoplasms with non-endocrine characteristics [33-35]. The immunoblots shown here (Fig. 3) confirm the expression of NSE by nonendocrine lung tumor cells. Thus, while the determination of serum levels of NSE and SYN (released into the circulation from necrotic cells) may serve to monitor responses of lung cancer to therapy $[36,37]$, these molecules cannot be used as absolute criteria for diagnostic purposes to distinguish endocrine from nonendocrine lung tumors. The more limited cellular specificity of NCAM 140 contrasts with the more general expression of both NSE and SYN in other lung tumors and suggests that NCAM could be a reliable
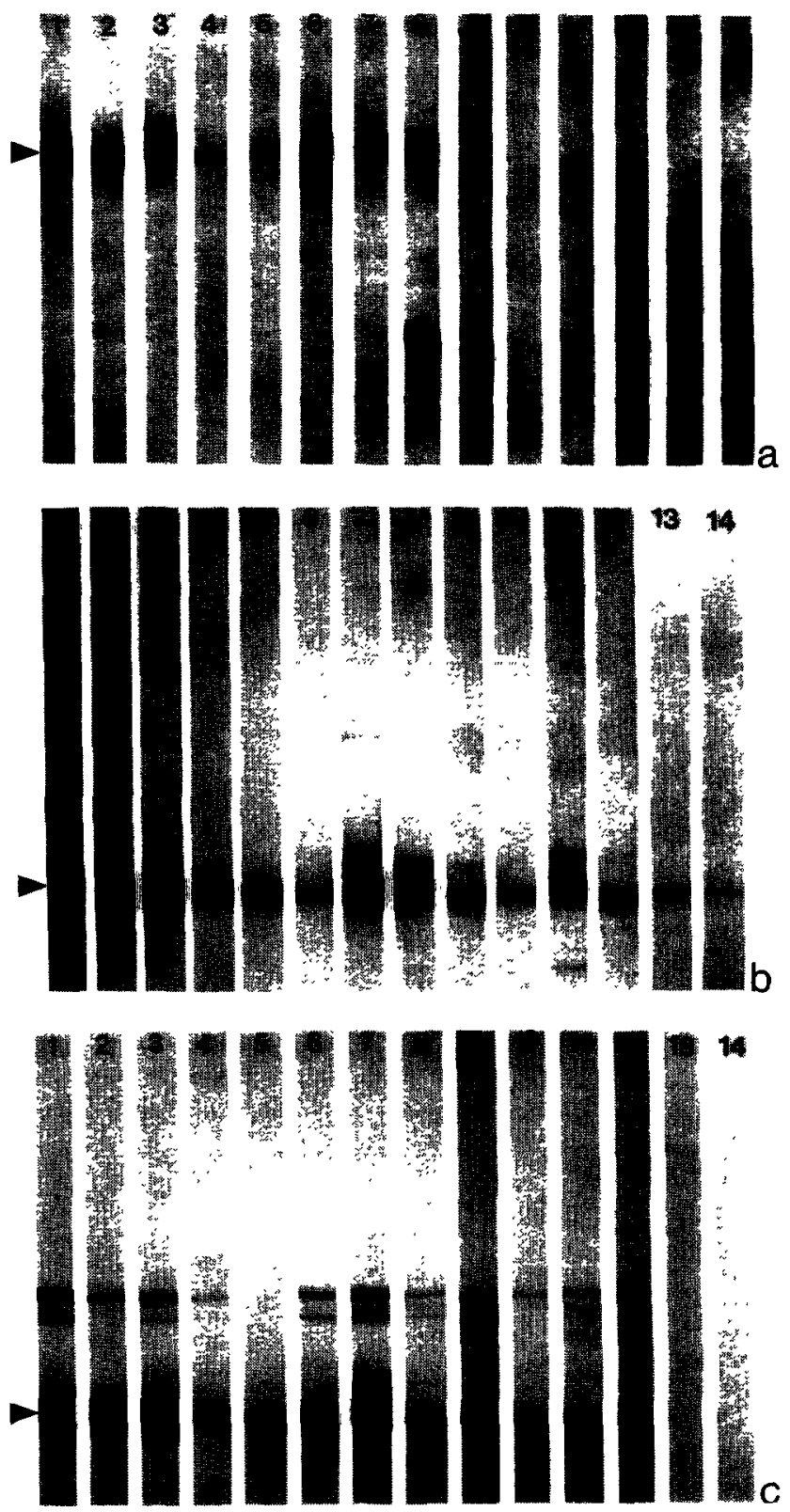

Fig. 3. Immunological identification of NCAM (a), NSE (b) and SYN (c) in different SCLC (lanes 1-7) and non-SCLC (lanes 8-14) cell lines. NCI-H60 (lane 1), NCI-N417 (lane 2), NCI-N592 (lane 3), SCLC-86M1 (lane 4), SCLC-21H (lane 5), SCLC-22H (lane 6), SCLC-24H (lane 7), LCLC-103H (lane 8), LCLC-97TM1 (lane 9), EPLC-65H (lane 10), EPLC-32Ml (lane 11), MST0-211H (lane 12), H125 (lane 13), A549 (lane 14). The amounts of proteins per lane were $70 \mu \mathrm{g}$ in (a) (except lane 3:35 $\mu \mathrm{g}$ ) and $100 \mu \mathrm{g}$ in (b) and (c). None of the specific bands were immunostained in controls when normal rabbit serum replaced specific antisera. The additional bands with larger molecular weight seen in the blots of SYN indicate the occurrence of protein polymers in spite of previous alkylation (see section 2). The arrowheads indicate NCAM (140 kDa) in (a), NSE (45 kDa) in (b) and SYN $(38 \mathrm{KDa})$ in (c).

diagnostic guide for both small and large cell lung carcinomas.

Surface markers such as NCAM possess a further advantage compared with intracellular molecules: they are 
accessible to externally applied antivodies. Such markers could be used in other clinical applications: we suggest they could be used for immunoscintigraphy to detect both primary tumors and metastases, even when these occur in unexpected (ectopic) tissues. Secondly, they could be used as probes to target drugs to tumor cells. Thus with suitable antibodies NCAM could serve as an ideal tool for diagnosis. In addition antibodies against NCAM 140 could be used in the histological and cytological diagnosis of biopsies or bone marrow aspirates, etc., together with general markers like NSE and SYN for the differential diagnosis of small cell and large cell carcinoma from other lung cancer forms.

After completion of this manuscript, a number of reports describing the specificity of several monoclonal antibodies (Mabs) previously generated against SCLC in different laboratories were published [38-41]. These suggest that some of these antibodies in fact recognise epitopes present on NCAM. It was suggested that one such Mab provided a well-needed addition to immunomarkers capable of distinguishing SCLC from non-SCLC, in agreement with our opinion that polyclonal anti-NCAM antibodies could be a useful diagnostic tool. Similarly, the potential therapeutic use of polyclonal anti-NCAM antibodies suggested here, is supported by a recent report [39] describing the use of a Mab, directed against the carbohydrate epitope common to NCAM and the ganglioside GD2 for immunotherapy and targeted radiotherapy. Another of these studies [41] on the SCLC H69 cell line showed the presence of two NCAM isoforms of 180 and $140 \mathrm{kDa}$ and also high levels of polysialic acid, which was suggested to be implicated in the invasive behaviour of these tumors. However, the present data on 7 separate SCLC cell lines showing the predominant or exclusive presence of NCAM 140 suggest that expression of multiple NCAM isoforms may not be a general phenomenon.

Acknowledgements: The authors are grateful to Drs Jon Askaa (Dakopatts, Denmark), R. Jahn (Martinsried, FRG) and G. Rougon (Marseille, France) for the generous gifts of antibodies. We thank Mrs M. Rudolf and Mr W. Podschuweit for expert technical assistance and Mrs B. Mader for typing this manuscript. This study was supported by Land Baden-Württemberg (Forschungsschwerpunkt 32) and Deutsche Krebshilfe.

\section{REFERENCES}

[1] Havemann, K. (1988) in: Progress in Cancer Research and Therapy, vol. 35 (Fresciani, F., King, R.J.B., Lippman, M.E. and Raynaud, J.P. eds) pp. 514-525, Ravens Press, New York.

[2] Marangos, P.J. and Schmechel, D.E. (1987) Annu. Rev. Neurosci. 10, 269-295.

[3] Wiedenmann, B., Kuhn, C., Schwechheimer, K., Waldherr, R., Raue, F., Brandeis, W.E., Kommerell, B. and Franke, W.W. (1988) Am. J. Clin. Pathol. 87, 560-569.

[4] Lloyd, R.V. (1987) Pathol. Annual 2, 69-90.

[5] Heitz, Ph.U. (1987) Curr. Top. Pathol. 77, 279-306.
[6] Langley, O.K., Aletsee, M.C. and Gratzl, M. (1987) FEBS Lett. 220, 108-112.

[7] Langley, O.K., Aletsee-Ufrecht, M.C., Grant, N.J. and Gratzl, M. (1989) J. Histochem. Cytochem. 37, 781-791.

[8] Bock, E., Jorgensen, O.S. and Morris, S.J. (1974) J. Neurochem. 22, 1013-1017.

[9] Bock, E., Jorgensen, O.S., Dittmann, L. and Eng, L.F. (1975) J. Neurochem. 25, 867-870.

[10] Gaardsvoll, H., Obendorf, D., Winkler, H. and Bock, E. (1988) FEBS Lett. 242, 117-120.

[11] Nybroe, O., Linnemann, D. and Bock, E. (1988) Neurochem. Int. 12, 251-262.

[12] Leube, R.E., Kaiser, P., Seiter, A., Zimbelmann, R., Franke, W.W., Rehm, H., Knaus, P., Prior, P., Betz, H., Reinke, H., Beyreuther, K. and Wiedenmann, B. (1987) EMBO J. 6, 3261-3268.

[13] Südhof, T.C., Lottspeich, F., Greengard, P., Mehl, E. and Jahn, R. (1987) Science 238, 1142-1144.

[14] Thomas, L., Hartung, K., Langosch, D., Rehm, H., Bamberg, E., Franke, W.W. and Betz, H. (1988) Science 242, 1050-1053.

[15] Bepler, G., Jaques, G., Neumann, K., Aumüller, G., Gropp, C. and Havemann, K. (1987) J. Cancer Res. Clin. Oncol. 113 $31-40$.

[16] Bepler, G., Jaques, G., Havemann, K., Koehler, A., Johnson, B.E. and Gazdar, A.F. (1987) Cancer Res. 47, 1883-1897.

[17] Bepler, G., Jaques, G., Koehler, A., Gropp, C. and Havemann, K. (1987) J. Cancer Res. Clin. Oncol. 113, 253-259.

[18] Bepler, G., Koehler, A., Kiefer, P., Havemann, K., Beisenherz, K., Jaques, G., Gropp, C. and Haeder, M. (1988) Differentiation 37, 158-171.

[19] Gazdar, A.F., Carney, D.N., Russel, E.K., Sims, H.L., Baylin, S.B., Bunn, P.A., Guccion, J.G. and Minna, J.D. (1980) Cancer Res. 40, 3502-3507.

[20] Rougon, G. and Marshak, D.R. (1986) J. Biol. Chem. 261, 3396-3401.

[21] Navone, F., Jahn, R., Di Gioia, G., Stukenbrok, H., Greengard, P. and De Camilli, P. (1986) J. Cell Biol. 103, 2511-2527.

[22] Sternberger, L.A. (1986) Immunocytochemistry, 3rd edn, John Wiley and Sons, New York.

[23] Lane, L.C. (1978) Anal. Biochem. 86, 655-664.

[24] Schilling, K. and Aletsee-Ufrecht, M.C. (1989) Anal. Biochem. 177, 203-206.

[25] Sheppard, M.N., Corrin, B., Bennett, M.H., Marangos, P.J., Bloom, S.R. and Polak, J.M. (1984) Histopathology 8, 171-181.

[26] Pearse, A.G.E. (1969) J. Histochem. Cytochem. 17, 303-313.

[27] Walts, A.E., Said, J.W., Shintaku, I.P. and Lloyd, R.V. (1985) Am. J. Clin. Pathol. 84, 273-277.

[28] Wilson, B.S. and Lloyd, R.V. (1984) Am. J. Pathol. 115, 458-468.

[29] O'Connor, D.T. and Deftos, L.J. (1986) N. Engl. J. Med. 314, 1145-1151.

[30] Lee, I., Gould, V.E., Moll, R., Wiedenmann, B. and Franke, W.W. (1987) Differentiation 34, 115-125.

[31] Marangos, P.J., Gazdar, A.F. and Carney, D.N. (1982) Cancer Lett. 15, 67-71.

[32] Said, J.W., Vimadalal, S., Nash, G., Shintaku, I.P., Heusser, R.C., Sassoon, A.F. and Lloyd, R.V. (1985) Human Pathol, 16, 236-240.

[33] Haimoto, H., Takahashi, Y., Koshikawa, T., Nagura, H. and Kato, K. (1985) Lab. Invest. 52, 257-263.

[34] Nesland, J.M., Holm, R., Johannessen, J.V. and Gould, V.E. (1986) J. Pathol. 148, 35-43.

[35] Pahlman, S., Esscher, T. and Nielsson, K. (1986) Lab. Invest. $54,554-560$

[36] Carney, D.N., Marangos, P.J., Ihde, D.C., Bunn, P.A., Cohen, M.H., Minna, J.D. and Gazdar, A.F. (1982) Lancet i, 583-585.

[37] Jaques, G., Bepler, G., Holle, R., Wolf, M., Hannich, T., Gropp, C. and Havemann, K. (1988) Cancer 62, 125-134. 
[38] Patel, K., Moore, S.E., Dickson, G., Rossell, R.J., Beverley, P.C., Kemshead, J.T. and Walsh, F.S. (1989) Int. J. Cancer 44, 573-578.

[39] Patel, K., Rossell, R.J., Pemberton, L.F., Cheung, N.K., Walsh, F.S., Moore, S.E., Sugimoto, T. and Kemshead, J.T. (1989) Br. J. Cancer 60, 861-866.
[40] Kibbelaar, R.E., Moolenaar, C.E.C., Michalides, R.J.A.M., Bitter-Suermann, D., Addis, B.J. and Mooi, W.J. (1989) J. Pathol. 159, 23-28.

[41] Moolenaar, C.E.C.K., Muller, E.J., Schol, D.J., Figdor, C.G., Bock, E., Bitter-Suermann, D. and Michalides, R.J.A.M. (1990) Cancer Res. 50, 1102-1106. 